\title{
The Effect Of Rotation, Mass, Distance And Wide End of The Stem Forging Against The Thinness of "Jagung Titi" on The Performance of The Forging Corn Mechanism
}

\author{
Yohanes B. Yokasing, Amiruddin Abdullah, Antonius Pangalinan \\ \{yohanesyokasing12@gmail.com, amiruddinabdullah90@yahoo.co.id, \\ antoniuspangalinan@yahoo.com\}
}

Jurusan Teknik Mesin Politeknik Negeri Kupang, Jl. Adisucipto, Penfui Kupang

\begin{abstract}
Abtract. "Jagung Titi" is a traditional food product of Lamaholot tribes. It is made by process of corn seeds are roasted until cooked and continued with forged to thin. During this process the forging used traditional technology in the form of a pair of stones, one as a foundation and other stones are used for forging (still manual). For that, alternative technology is examined as the mechanism of forging corn. The ability of this wrought corn mechanism is influenced by the rotation, mass, distance and wide end of the stem forging against thinness "jagung titi" corn of the wrought corn mechanism. The results of the study show that the greater the rotation, the mass (the stem of forging), and small of wide end the stem forging.
\end{abstract}

Keywords: Corn seeds, Jagung Titi, Forging Corn Mechanism

\section{Introduction}

Jagung titi is a traditional food product owned by the people of Lamaholot (local communities or from East Flores, Lembata and Alor) in East Nusa Tenggara (NTT). To make jagung Titi; Corn seeds are roasted (fried without oil) until cooked, then held (forged) using a pair of stones (one as the foundation and the other is moved from the top to the bottom of the corn seed to be pointed). Leoni Perada, said that, "to produce the jagung titi's tasty, and crisp, it takes special skills, which are built specifically by the habit that the ancestors inherited".

Results of field survey 2018, others are obtained; tasty and crisp of jagung titi, depends heavily on the maturity level of corn roasted, thin, and intact for each seed corn. Lamaholot Society, producing the Jagung Titi still traditionally. Jagung titi is manufactured through 2 phases namely; First stage, corn seeds to taste in the frying pan or roasted until cooked (brown corn color). The maturity of the roasted corn seeds is also made to be able to be tested and on the contrary, the results of the ripen no longer melted but crushed.

The second stage forge, which originates from; Corn seeds are ripe (while roasted) raised slightly using a hand or spoon, placed only 2 or 3 seeds above the foundation stone and Dititi, using stone. A ripened delay is no longer a disintegrating but crushed. This stage is carried out continuously until the corn is drained. The amount of corn seeds each time is limited to consider the burden of stone mass and pursue energy and the whole corn of the rice, the result is taken slightly by hand or spoon, placed only 2 or 3 seeds on the stone foundation and being held, Using rocks. A ripened delay is no longer a disintegrating but crushed. 
The energy in motion must adjust to the magnitude of the stone mass that is moving against the ability to be able to place (thin and entirety) the resulting Maize (field survey results, 2018). The technique of making jagung titi traditional way, in the second stage, more requires a lot of energy, time, perseverance and risky. It is a problem that is troublesome, and difficult, when the demand for a lot of product capacity, with a short time. Many product capacities also require readiness in the form of energy, time and many operators. Therefore, the alternative technology is examined that answers the above problems. The alternative technology is the mechanism to compose rotation movement (rotation) into a vertical translation, to forge.

This study with the title, "The effect of rotation, mass, distance and breadth of the tip of the rod to the thinness of "Jagung Titi's" mechanism of forge corn". Round, mobs stem, turned into load and style, directed (focused) with the edge of the rod tip and directed, against the seeds of corn that are on the runway, in reaching the thinness. The small power manifested in the motion of rotation directly affects the style of the outcome. This is reinforced with the study conducted by Darmawansyah, 2015, produce, "the greater the round of the machine given then the greater the power is effective". It was done in the study titled, "Influence of loading and rotation of machine against torque and power produced machine Matari MGX200/SL"

The mass of stem forging affects by the acceleration of gravity transformed into a burden, and is added to the movable and directed (positioned) slightly centralized (displacing) style at the end of the forging rod. Positioning the style, the weight is slightly centered and has the distance (farthest position and forging position). Distance will provide and can increase the voltage that affect the ability of the forge. According to Ari Wibowo, et all, 2014, in the study titled " Effect of load-to-voltage position and rotation of the bottom edge of the bridge" Boomerang Bridge ", said that," the closer the load position to the rod is tested, the greater the voltage and vice versa ". Therefore, the need to study to get the dimensions and size of the appropriate component mechanism as needed.

\section{Literature Review}

\subsection{Jagung Titi}

Jagung Titi is a food product derived from corn seeds and has a flat shape, which is made from corn seed is roasted and woven (forged) on a pair of stones or through the process of corn. For more details, the following figure 1 appears. 


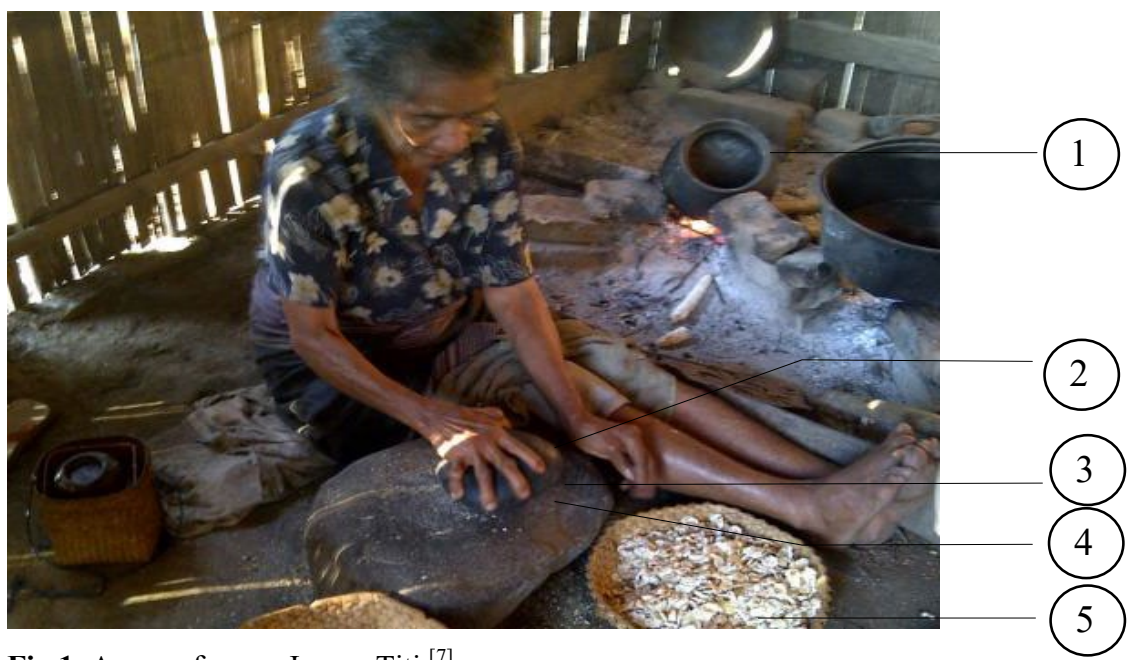

Fig 1. A mom forge a Jagung Titi ${ }^{[7]}$

Description of figure 1 :

(1) Wok or roasted container

(2) Forging (handheld) stone

(3) Place or position of corn seed forged

(4) Forging ground stones

(5) Jagung titi

Corn seed is forged with raw or dried corn seeds that have a power of flowers and capable of thin and intact. The thinness of the corn is due to the burden (mass and style) of forging, wrought stones and forging foundations. Jagung titi is still traditionally made using an absolute technology and requires a lot of effort and time. The manufacture of Jagung titi through two stages, the first stage of the corn seed is disanggrai until ripe that marked the color of the corn seeds changed (a bit brownish), and the dimension of corn seeds develops (larger). On the next stage or the second stage of corn seed that has been ripe roasted in small quantities and placed 2 or 3 seeds on the runway stone, and dititi to the flattened. Next, the result is shifted, and another corn seed is put, in the same amount to be done again, this process repeatedly until the corn seeds are roasted out.

In the second stage the corn is forged using a pair of stones, one as the base and the other as a forging. The stone as a forging is used stone that can be held by the palms on the top. At the top of the rock held to form a semicircular, the lower part is also semicircular, but slightly at the end of the bottom in contact with the corn that was forged near or in contact with the foundation stone has Flat surface, an area of four corn. While the foundation stone has a flat surface at the top of the forging position, and the bottom is also flat, so it is easy to laying. The base stone size has a much larger, thicker, and heavier dimension and allows not to shift while forging

The forging of corn titi requires energy and patience, a forging is required to release the power while lifting and directing the wrought stone and provide energy in the form of encouragement and directed corn seed that is to be forged, and the operator holds So the load really leads to the seed of a forged corn. If you have not succeeded to remove the operator, you can lift the forged stone as high as expected to forge again.

\subsection{Jagung Titi Mechanism}


The mechanism of Jagung Titi is a specific mechanism, which is designed to produce the final movement in the form of vertical downward movement for the forging. In this mechanism there are a series of components such as, drive motors, transmission reducer, puli, belt, shaft, stem, transmission disc, modifier arm, steering, and forging bars, seen in Figure 1. The components of this mechanism have their own construction geometry and function, as a whole. As a whole mechanism there is a fixed component (silent) and there is a moving component.

If one of the connecting rods is fixed and the movement of the other connect rod to its new position will cause each other connecting rod to move to certain positions that has been predicted, the system is a restricted kinematic chain ${ }^{[5]}$. In the forging mechanism, the shaft components are driven by the motor power scrapers associated with the reducer, transmitted by the transmission disc, and supported by other components that cause the rod to move the translation vertically ( $t i t i)$ Directed forging.

In a examined mechanism, it has components that produce or possess, some variables that affect the performance of the mechanism. Those variables are;

a. Round

The rotation comes from the power, resulting from the motor of the roaches. Power is transmitted through the transmission component (belt, reducer, and Puli) in the translation component. Daya was the rapid effort that was done by the unity of time ${ }^{[2]}$.

The larger round of the given machine then the greater the power is effective ${ }^{[3]}$. It was done in the study titled, "Influence of loading and rotation of machine against torque and power produced machine Matari MGX200/SL".

It is supported also, the study conducted by Gertruda Octya, et all, 2017, in the study titled, "The effect of rotation speed on performance on the Pinang Peeler", it was produced that, "the most optimal rotation speed obtained at the treatment of D1 With a 5 inch puli diameter of $2080 \mathrm{rpm}$, the highest capacity of effective tool obtained at D1 treatment with 5 inch puli diameter of $99.1 \mathrm{~kg} / \mathrm{h}$ while the lowest effective capacity of tool is obtained at the treatment D3 with a diameter of a 7 inch Puli of $84.5 \mathrm{~kg} / \mathrm{hr}$. This means that a smaller puli has a greater rotation than the larger diameter.

b. Massa

Mass exhibits the inertial properties of objects. The masses are what an object is in while being styled from the bottom, will give resistance, and as behind from the other side, it requires a style that must be greater than what it belongs to. Mass is usually symbolized by $\mathrm{m}$ with units such as kilograms ( $\mathrm{kg})$, gram (GR), Ton, and others. Otherwise heavy is a style that works on an object as a pull by the Earth or other large object.

Weights that have weights will affect the resulting load, where the load is getting larger than straight with the resulting voltage and vice versa. Similarly the location of the centralized load will maximize the voltage work towards the target larger. Influence of Load position against voltage and rotation of the bottom edge of the bridge" Boomerang Bridge ", said that," the closer the load position to the rod is tested, the greater the voltage and vice versa ${ }^{[9]}$.

c. Surface Area

The surface area is the dimension of the lower end surface of the rod, as the tension concentration. Voltage is a mixture of load (mass) and force (power), which is applied to the seed of corn. The surface is flat and circular horizontally and aligned with the surface of the runway.

Voltage is directly proportional to the magnitude of the working force, and is reversed with reverse towards the area ${ }^{[8]}$. This means the voltage value will depend on the magnitude of the style, the magnitude of the working style depending on the area of the cross. The extent 
of a working style surface, the resulting voltage is reduced and the less or less the voltage surface area will increase or greater as the surface area decreases.

\section{d. Distance Forge}

The forging distance is the farthest position where the rod's farthest boundary moves against the runway. The distance position also determines the ability in connection with the application of voltages that have forged stems and add gravity acceleration. Stems are influenced by distance, at a certain distance will have high forging capability (capable of thinner) and other distances will be reduced, due to the distribution of voltage in the translation movement.

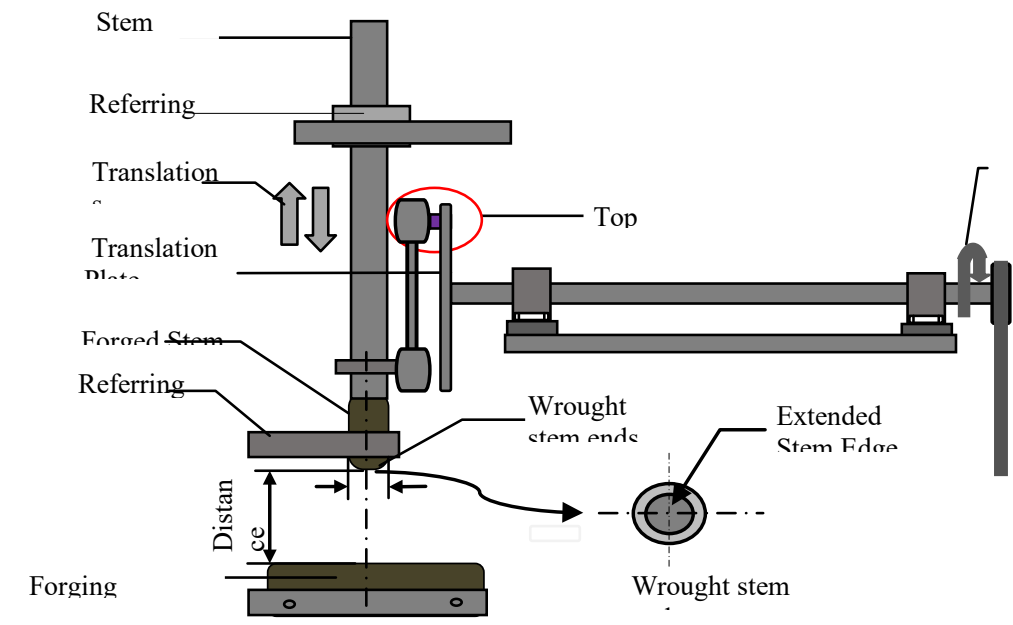

Fig. 2. Schematic Diagram of Jagung Titi

\section{Research Methods}

\subsection{Machine Jagung Titi}

Machine Corn Titi has a vertical motion mechanism, consisting of components; Motor of the rounder, transmission of the power of the gear, chain, shaft, disc, modifier arm, stem and forearm, and frame

\subsection{How to Work Jagung Titi Machine}

The motor is switched on, the motor shaft round is forwarded to the shaft through the gear and chain, the shaft forwards to the transmission disc, the transmission plate continues to the The vertical movement is a forging movement, which is used for forging corn.

\subsection{Limitation of Reseach}

a) Round of transmission plates, used 2 namely $40 \mathrm{rpm}$ and $50 \mathrm{rpm}$

b) Surface area Titi $157 \mathrm{~mm} 2$ (Midline Circle $50 \mathrm{~mm}$ ) and $188.4 \mathrm{~mm} 2$ (Midline Circle 60 $\mathrm{mm})$

c) Final mass forging, used $5 \mathrm{~kg}$ and $6 \mathrm{~kg}$

d) Corn seeds 
- Type of seeds used must be the same, in this study using corn Hebrida

○ The size of seeds is approximately equal

e) The level of maturity

○ Many corn that is targeted each study equals 100 grams

$\circ$ Temperature $\pm 60^{\circ} \mathrm{C}$

- Containers (used pans) are the same as cast iron pans

- Duration 12 minutes

- At the time of the process the temperature to $\pm 40^{\circ} \mathrm{C}$

f) Amount of corn seeds every time 4 seeds

\subsection{Data Retrieval Stages}

a) corn ripe seed roasted results lifted from a frying pan

b) placed on the runway, without any other corn seeds

c) The corn of the result is rolled on places provided

d) conducted measurements and data collection

\section{Results and Discussion}

\subsection{Results}

Table 1. Research Data

\begin{tabular}{|c|c|c|c|c|c|}
\hline No & Round (rpm) & Massa $(\mathrm{kg})$ & $\begin{array}{l}\text { Surface Area } \\
\quad(\mathrm{mm} 2)\end{array}$ & $\begin{array}{c}\text { Thinness } \\
(\mathrm{mm})\end{array}$ & Intact or not intact \\
\hline & 30 & 5 & 157 & 1,4 & intact \\
\hline & & & & 1,6 & intact \\
\hline & & & & 1,5 & intact \\
\hline & & & 219 & 1,3 & intact \\
\hline & & & & 1,3 & intact \\
\hline & & & & 1,4 & intact \\
\hline & & 6 & 157 & 1,3 & intact \\
\hline & & & & 1,4 & intact \\
\hline & & & & 1,4 & intact \\
\hline & & & 219 & 1,4 & intact \\
\hline & & & & 1,3 & not intact \\
\hline & & & & 1,4 & intact \\
\hline & 40 & 5 & 157 & 1,3 & intact \\
\hline & & & & 1,3 & intact \\
\hline & & & & 1,4 & intact \\
\hline & & & 219 & 1,2 & intact \\
\hline & & & & 1,2 & not intact \\
\hline & & & & 1,2 & intact \\
\hline & & 6 & 157 & 1,1 & intact \\
\hline & & & & 1,2 & intact \\
\hline & & & & 1,2 & intact \\
\hline & & & 219 & 1,1 & intact \\
\hline & & & & 1 & intact \\
\hline & & & & 1,1 & not intact \\
\hline
\end{tabular}

Description of table : - The mass end of the forging

- Surface area: $157=$ middle line $50 \mathrm{~mm}$ circle

188.4 = middle line Circle $60 \mathrm{~mm}$ 


\subsection{Discussion}

At the $30 \mathrm{rpm}$ round, the mass of $5 \mathrm{~kg}$, the surface area is $157 \mathrm{~mm} 2$, the thinnest result of $1.4 \mathrm{~mm}$ and the thickest $1.6 \mathrm{~mm}$. For the $40 \mathrm{rpm}$ round, the masses are $5 \mathrm{~kg}$, the surface area is $157 \mathrm{~mm} 2$, the thinnest of the forged $1.3 \mathrm{~mm}$ and the thickly $1.4 \mathrm{~mm}$, with the condition of the corn intact While at a mass of $6 \mathrm{~kg}$, for a round of $30 \mathrm{rpm}$, the surface area of $157 \mathrm{~mm} 2$, the thinnest of forged $1.3 \mathrm{~mm}$ and the thickness of $1.4 \mathrm{~mm}$, the condition of the forging of the corn is not intact. For $40 \mathrm{rpm}$ rounds, the surface area is $157 \mathrm{~mm} 2$, the thinnest is $1.1 \mathrm{~mm}$ and the thickness is $1.2 \mathrm{~mm}$.

At a surface area of $188.4 \mathrm{~mm}^{2}$, with a rotation of $30 \mathrm{rpm}$, a mass of $5 \mathrm{~kg}$, the thinnest of wrought $1.3 \mathrm{~mm}$ and the thickest $1.4 \mathrm{~mm}$. For the $40 \mathrm{rpm}$ round, the mass of $5 \mathrm{~kg}$, the area, the thinnest wrought result is $1.3 \mathrm{~mm}$ and the thickest $1.4 \mathrm{~mm}$. While in the mass of $6 \mathrm{~kg}$, to round 30 , the thinnest wrought result is $1.3 \mathrm{~mm}$ and the thickest is $1.4 \mathrm{~mm}$. For a round of $40 \mathrm{rpm}$, the thinly wrought is $1 \mathrm{~mm}$ and the thickest $1 \mathrm{~mm}$, with the condition of the forging of the corn is not intact.

\section{Conclusion and Suggestion}

\subsection{Conclusion}

The thinnest wrought result is achieved in the round of $40 \mathrm{rpm}$, with a mass of $6 \mathrm{~kg}$, at an area of $188.4 \mathrm{~mm}^{2}$, the condition of corn is not intact anymore, while the thinness is reduced (thicker) in the round $30 \mathrm{rpm}$, the mass of $5 \mathrm{~kg}$, the surface area of $157 \mathrm{~mm}^{2}$, the thinly wrought result $1.4 \mathrm{~mm}$ and the thickest $1.6 \mathrm{~mm}$.

\subsection{Suggestions}

The rotating speed of the transmitting disc to the runway is very influential in the ability to forge corn, to achieve more

\section{References}

[1] BPS, 2010, East Nusa Tenggara in Figures 2010, BPS Prop. Kupang, Cv. Natalia Kupang

[2] Bueche J. Frederick, 1989, Physics, Eighth edition, Schaum book series, Theory and questions, Jakarta, Erlangga

[3] Darmawansyah, 2015, influence of loading and rotation of the machine against the torque and power produced machine Matari MGX200/SL, thesis, mechanical Engineering study Program, Faculty of Engineering, University of Muhammadiyah Pontianak

[4] Munarso J.S. and Miskeh, 2009, Diversified Cassava-Based Food. Cassava Technological Innovation and Development policy, Agency for Research and Development of Agriculture Research and Development Center of Food Crops. 2009.

[5] Martin H. Goerge, Setiyobakti, 1984, Kinematics and Technical Dynamics, Second Edition, Jakarta, Erlangga.

[6] Octya Gertruda, Munir Son of Achwil, Rohanah, 2017, Effect of Rotation Speed on Performance at Pinang Peeler, Agricultural Engineering J. Food Engineering and Pert., Vol. 5 (Supp. 1) Second, Jakarta, Erlangga.

[7] Pos Kupang, 2015, We Titi Until Hands Blister, National Daily Pos Kupang, Sunday, July 5, 2015

[8] Sonawan Hery, 2009, Machine Element Designing, Alfabeta Bandung 
[9] Wibowo Ari, Nuralinah Devi, Wisnumurti, Widya Erwin, 2014, Effect of load position on the voltage and rotation of the lower edge Trunk Bridge "Boomerang Bridge", Journal of Civil Engineering/Volume 8, No. 2 